\title{
The effect of construction frequency and native transfer on second language knowledge of the syntax-discourse interface
}

\author{
ROUMYANA SLABAKOVA \\ University of Iowa and University of Southampton
}

Received: September 1, $2012 \quad$ Accepted for publication: May 1, 2013

\begin{abstract}
ADDRESS FOR CORRESPONDENCE
Roumyana Slabakova, Department of Modern Languages, University of Southampton, Building 65, Avenue Campus, Southampton SO17 1BF, UK. E-mail: r.slabakova@ soton.ac.uk
\end{abstract}

\begin{abstract}
This article investigates knowledge of discourse-conditioned left dislocations in the interlanguage competence in Spanish and English second language learners. Although Spanish clitic left dislocation (CLLD) and English topicalization are functionally very similar, they differ in that the former but not the latter requires the dislocated phrase to be clitic doubled. In contrast, the fronted focus (FF) construction is functionally and syntactically similar in the two languages. Two experimental studies investigated knowledge of the syntactic form and discourse appropriateness of CLLD and topicalization, using knowledge of FF as a baseline. English-native learners of Spanish were successful in acquiring CLLD as well as FF. However, Spanish-native learners of English demonstrated no knowledge of English topicalization even at near-native levels of proficiency, whereas they did well on the transferable FF. These results are examined in the light of the interface hypothesis. It is argued that construction frequency in the input and transfer from the native language, but only those two factors together, can explain the experimental results.
\end{abstract}

Since Sorace (2003), the interface hypothesis (IH) has provided an influential explanation of second language (L2) development within the generative L2 acquisition paradigm (for a review of its original claims and development, see Sorace, 2011). Like other generative approaches, this proposal is rooted in a modular view of language architecture, capitalizing on the current attention to linguistic interfaces (for reviews, see Montrul, 2011; Rothman \& Slabakova, 2011; White, 2009). Generally speaking, interfaces are points of interaction between modules or systems, where output representations of one module or system must be interpreted by another. Within the language architecture, the internal interfaces, as this term is widely used, are those between different modules of language, such as the syntaxsemantics interface and the morphology-syntax interface. External interfaces, in

(C) Cambridge University Press 2013 0142-7164/13 \$15.00 
Slabakova: Second language knowledge of the syntax-discourse interface

contrast, involve language and nonlinguistic cognitive systems, and the one most often investigated is the syntax-discourse interface.

Building on the concept of interfaces, the IH proposes a theory of L2 acquisition pathways, identifying challenging areas of the grammar. A definite strength of this hypothesis is its integrating notions from psychology and cognitive science into the minimalist linguistic understanding of the grammar. In general terms, the IH predicts that L2 learners will have more difficulty in acquiring properties related to external interfaces than properties related to internal interfaces. In its current form (Sorace, 2011), the IH appeals to processing related explanations for the performance differences noted in near-native speakers of a L2. The IH maintains that there is a significant cognitive cost to having more than one grammar represented in the mind. It draws on the concept of inhibitory control (e.g., Green, 1986, 1998), which has long been discussed in psycholinguistics as a crucial factor in bilingual performance. Inhibitory control refers to the cognitive deactivation or inhibition of one grammatical system in the mind/brain when the other grammatical system is called upon to perform a given linguistic task. Linguistic inhibition is indispensable for bilinguals under the generally accepted idea that all grammars in the mind of bilinguals are simultaneously activated (Kroll, Bobb, Misra, \& Guo, 2008; Marian \& Spivey, 2003; for a review, see Bialystok, Craik, Green, \& Gollan, 2009). Although this line of argumentation is often made for bilinguals in general, adult L2 acquirers represent one particular case of bilingualism. As is the case with all L2 speakers, they must use (at least some) cognitive resources to suppress their first language (L1) grammar when processing the L2, thereby encumbering memory systems, executive function, and allocation of attentional resources. Therefore, even if their underlying L2 linguistic representations are nativelike, there may still be some target-deviant variability in performance attributable to bilingual processing. It may be even harder for adult learners to inhibit their native grammar, as compared to child L2 learners and simultaneous bilinguals, because of some loss of mental flexibility with age. The IH builds on this bilingual cognitive effect, predicting that even the most advanced learners (i.e., near natives) will have residual L1 effects, indeterminacy, or optionality in performance. Residual optionality refers to the situation where an L2 speaker maintains two values of the same parametrically opposed property (e.g., clitic and no clitic in clitic left dislocation [CLLD]) in their grammar at the same time and accesses them somewhat randomly in performance (Sorace, 2005).

According to Sorace and Filiaci (2006) and Tsimpli and Sorace (2006), there is a principled difference between purely syntactic computations that derive from representational requirements of internal linguistic interfaces and the mapping between linguistic and extralinguistic information that happens at the syntaxdiscourse interface. The latter combines linguistic representations with broader discourse representations that evaluate external pragmatic conditions on contextual appropriateness. Discourse tracking and the subsequent incorporating of nonlinguistic (but relevant) information into the linguistic meaning computation is argued to impose higher demands on processing resources. The IH does not contend that L2ers are a priori unable to acquire targetlike representations for syntax-discourse properties; rather, residual optionality, as evidenced in linguistic performance, arises as a by-product of the extra burden these properties entail for 
Slabakova: Second language knowledge of the syntax-discourse interface

finite cognitive resources. Because the $\mathrm{IH}$ is based on the cognitive consequences of bilingualism, it makes predictions in addition to and beyond L1 transfer. That is, some level of residual optionality is expected for syntax-discourse properties regardless of L1-L2 pairings, although L1 influence as a co-occurring variable is not precluded.

The IH has been supported with an impressive array of data to date, mainly from the L2 acquisition of reference in Romance languages. Belletti, Bennati, and Sorace (2007) present a prime example of difficulties and optionality even for near-native speakers. There is a discourse preference for an overt pronoun in null subject languages to signal a topic shift. In processing such topic shifts, Italian near-native speakers were found to interpret the overt pronominal subject of the embedded clause as coreferential with the lexical subject of the main clause $30 \%$ of the time, whereas the natives only interpreted it in this way $5 \%$ of the time, a significant difference. Thus, the Italian near natives in this study were argued to be less sensitive than the native speakers to topic shift discourse situations.

Roberts, Gullberg, and Indefrey's (2008) recent study investigated the online and offline performance of Turkish (a null subject language) and German (nonnull subject) learners of Dutch (another nonnull subject language) with respect to ambiguous pronoun resolution. The Turkish speakers chose a clause-external antecedent for an ambiguous pronoun more often than did the German learners. Thus, Turkish learners were essentially showing L1 transfer in the offline task of this study. However, in the online task, both advanced learner groups diverged from native speaker behavior, suggesting that processing of ambiguous pronouns where the choice of antecedent depends on the context is hard, even if the native language of the learners gives them an acquisition advantage. This finding also illustrates the IH claim that near-native speakers can, in certain cases, have nativelike representations but nonnativelike performance.

However, because more properties at the syntax-discourse interface across a wider array of L1-L2 pairings are being examined, the results have been more mixed, and some of them have been interpreted as challenges to the IH. A significant number of very recent studies have provided evidence of nativelike L2 performance for external interface properties. To cite a few, Rothman (2009) inspects contrastive focus and pronominal referential subject use in highly advanced L2 Spanish. He shows that some learners perform identically to the native controls across several tasks. Iverson, Kempchinsky, and Rothman (2008) examine discourse-sensitive mood alternations (indicative vs. subjunctive) with epistemic predicates in advanced L2 Spanish, showing that some learners perform like native speakers. Hopp (2009) investigates ultimate attainment at the syntax-discourse interface, specifically, discourse-related word order optionality in German. His results indicate that convergence at the syntax-discourse interface is in principle possible in adult L2 acquisition, both in offline knowledge and in online processing, even for L1 English speakers, whose L1 does not correspond to L2 German in discourse-to-syntax mappings. More studies documenting success at discourse-dependent left dislocations (LDs; Bohnacker, 2010; Donaldson, 2011, 2012; Ivanov, 2012; Valenzuela, 2005, 2006) are reviewed later in this article.

There is no doubt that Sorace and colleagues' IH is a reasonable, principled, and eminently testable hypothesis for explaining the effect nonnative processing 
Slabakova: Second language knowledge of the syntax-discourse interface

can have on L2 acquisition and performance. Because recent research results have offered confirmation as well as challenges to the $\mathrm{IH}$, we can realistically accept that there are some properties at the syntax-discourse interface that are a significant source of residual optionality in nonnative grammars, whereas others are not so challenging to master and process. This could be true for all interfaces, as White (2009) points out. At this stage of accumulation of data, it is important to look for principled reasons why the findings are the way they are, in the acquisition of syntax-discourse. In principle, conflicting findings can be due to different methodologies employed in the testing of knowledge. They can be due to the differential syntactic difficulty of the constructions beyond the necessity to incorporate discourse information. They can certainly be due to the difficulty of tracking and incorporating the discourse information within the different linguistic representations. They can also be due to the exact configuration of native and target grammatical options allowed by the grammar, where targetallowed but dispreferred native strategies may be maintained indefinitely (Belletti et al., 2007). Another important factor influencing L2 behavior could be the amount of evidence for a certain construction with which native speakers provide learners: in other words, construction frequency. Fortunately, there are research designs in which some of these factors can be examined while others are kept constant.

This article represents an attempt to reconcile the findings for and against the $\mathrm{IH}$ by looking at the same construction in two learning directions. I present comparable partial results from two larger studies examining the acquisition of CLLD by English-native learners of Spanish and the acquisition of topicalization by Spanish-native learners of English. These two constructions are functional equivalents and so conceivably of equal syntactic and discourse-pragmatic complexity. The experimental methods and procedures of both studies are the same, so no methodological differences can explain any differences in the findings. In both learning directions, L1 transfer is misleading for the learners. In both studies, fronted focus $(\mathrm{FF})$ is used as a baseline construction where transfer from the native language is possible. The crucial difference between the two learning directions is how often CLLD/English topicalization is encountered in the naturalistic input available to learners. To anticipate the main result of this comparison, evidence in the input as well as the native language will turn out to be the decisive factors for the success or failure of acquiring topicalization.

\section{TOPIC MARKING IN SPANISH AND ENGLISH}

Topic and focus are two pragmatic categories that build the sentential information structure (IS; Birner \& Ward, 1998; Chafe, 1976; Gundel, 1988b; Halliday, 1967; Lambrecht, 1994; Prince, 1992; Ward, 1988; Zubizarreta, 1998). When a linguistic constituent has been mentioned in the previous discourse or is known to the speaker and hearer (i.e., it represents shared/old information), it is called topic. Both Spanish and English can mark topic with a special construction, where the topicalized element is moved to the left periphery of the sentence, out of the neutral subject-verb-object word order. Although Spanish and English topicalizations have similar discourse functions, the crucial formal difference between the two 
Slabakova: Second language knowledge of the syntax-discourse interface

constructions is that, in Spanish, a clitic doubles the moved constituent (also known as "dislocate") and agrees with it in gender, person, and number. The name of this construction, widely accepted in the literature since Cinque (1990), is CLLD, as in (1). English has no clitics, and it does not allow a personal pronoun to double the moved constituent (2). In the examples below, the clitic is in italics and the dislocates are underlined.

(1) a. [Context: I need to buy a newspaper and some bread.] El periódico, lo compraré antes de ir al trabajo.

The newspaper CL.ACC buy.FUT.1SG before going to work

"The newspaper, I will buy before work."

b. [context: What did the movers do with the furniture?]

Las sillas las dejaron en el pasillo, pero no sé dónde están las mesas.

the chairs CL left.3pl in the hallway, but NEG know.1sg where are the tables

"The chairs they left them in the hallway, but I don't know what they did with the tables."

(2) a. [Context: I need to buy a newspaper and some bread.]

The newspaper, I will buy (*it) before work.

b. Monica: Did you eat the salad?

Alfred: The lettuce I ate (*it). I didn't like the olives.

Note that it is not obligatory that the dislocate be identical to the phrase mentioned in the discourse (i.e., the discourse antecedent), as in (1a) from Valenzuela (2005, p. 9) and (2a). In (1b) and (2b), the discourse antecedents are the furniture and the salad; the dislocates constitute only a subset of the antecedent (i.e., the chairs and the lettuce). Notice also that the discourse felicity of both topicalization and CLLD improves when the dislocate is compared to another mentioned nominal; that is, they are both contrastive (Gundel, 1988a).

The new or nonpresupposed information in the sentence is focus. Two types of focus are distinguished in the literature, presentational (i.e., information) focus and contrastive (i.e., identificational) focus (Gundel, 1988a; Kiss, 1998). ${ }^{1}$ The latter highlights a constituent for the purposes of contrast, usually correcting something that has just been asserted. Contrastive focus can be signaled by fronting of the focused constituent (FF) or by emphatic intonation, or frequently both. It is crucial for our purposes in this article that FF in Spanish does not use a doubling clitic (3), which makes it functionally and formally equivalent to English FF (4).

(3) [context: John bought the furniture]

S: LA ALFOMBRA compró (no los muebles)

"THE RUG he bought (not the furniture)."

(4) M: Did I take my jacket to be cleaned? I think I need to wear it today.

$\mathrm{N}$ : The SHIRTS you took to the cleaner's, not the jacket. Here it is in the closet.

In this article, I adopt the widely held view that the dislocate in English topicalization and FF form an argument (A)-dependency with an argument position inside the tense phrase (TP). This dependency has been captured by two basic means in the literature: by postulating movement of the dislocate from a TP-internal to a 
Slabakova: Second language knowledge of the syntax-discourse interface

left-peripheral position or by its base generation in the latter position and chain formation with an argument position.

On movement approaches, the surface position of the dislocate reflects an operation that copies the original element in a left-peripheral position and deletes the lower copy, or pronounces parts of it (e.g., Boeckx, 2003; Grewendorf, 2002; Grohmann, 2003). On base-generation approaches to English topicalization (e.g., Anagnostopoulou, 1997; Cinque, 1990; Frey, 2004), the dislocate is generated in the C-domain and an empty operator is generated in an argument position, which then moves at logical form (LF). The relation between the dislocate and the operator with its trace is then created by chain formation at LF. Both types of approaches manage to capture the connectivity effects of topicalization: although the fronted phrase is in a noncanonical position, it still retains close syntactic relations with the core $\mathrm{TP}$ and its arguments.

A common characteristic of movement and base-generation approaches is that they deal with IS notions through the usual narrow-syntactic means: featureassignment and movement to a functional projection for checking purposes. A qualitatively different approach to (dislocated) focus and topic originates in Reinhart (1981) and is developed by many, including Horvath (2010), Neeleman and van de Koot (2008), Neeleman, Titov, van de Koot, and Vermeulen, (2009), Reinhart (2006), Valduví (1992), Valduví and Vilkuna (1998), and Zubizarreta (1998). This other approach argues that topic and focus do not instantiate formal syntactic features and do not correspond to functional projections. Instead, these notions are involved exclusively in "discourse grammar," specifically in the mapping of syntactic structures to IS representations, and play no role in the syntactic computation deriving formal semantic representations. However, they interact with phenomena of the human language computation indirectly, via the syntax-discourse interface. Neeleman and van de Koot (2008) show that the movement is optional and targets various left-periphery positions. In the case of contrastive topics and foci (the type we are examining in this article), the movement of the phrases marks their domain of contrast (i.e., the material relevant to calculating the set of alternatives on which the contrast operates; Neeleman et al., 2009)

A fourth approach (López, 2009), which maintains elements from both featurebased treatments and interface-based treatments, proposes a pragmatic module of computation. This module yields an intermediate level of representation between the syntactic structure and the discourse structure where the features [ \pm antecedent] and [ \pm contrast] are assigned. Individual lexical items enter into the syntactic derivation, which proceeds in phases (Chomsky, 2001) and yields at the end of each phase (verb phrase and complementizer phrase [CP]) a syntactic object $\Sigma$. This syntactic object is then inspected by the pragmatics module, which assigns the relevant discourse features to constituents located in syntactic positions at the phase edge, yielding the IS $\Sigma[\mathrm{p}]$. These pragmatic structures are subsequently assembled into longer units of text in the discourse module, in the form of discourse representation structures. $^{2}$

Spanish and English FF have been analyzed essentially in parallel (Kempchinsky, 2008; Slabakova, Kempchinsky, \& Rothman, 2012). The constructions that have received some different analyses are English topicalization and Spanish CLLD, as in (1)-(2). There are syntactic differences between these constructions 
(Cinque, 1983): a specificity distinction present in Spanish but not in English; multiple possible dislocates in Spanish versus only one in English; occurrence in root and embedded clauses in Spanish while root only in English (except with bridge verbs); and sensitivity to strong islands only in Spanish but all islands in English. Anagnostopoulou (1997), trying to account for these differences and following van Haaften, Smits, and Vat (1983) and Demirdache (1991), compares English topicalization (she calls it contrastive left dislocation) to Romance CLLD. In her analysis, both constructions involve an adjoined left-dislocated phrase associated with an operator-variable chain. Clitics and null operators share similar operator properties. The asymmetries between the two constructions follow from the different adjunction sites of the left dislocated constituent: in contrastive left dilocation the phrase adjoins to CP whereas in CLLD the phrase adjoins to the inflection phrase. In Rizzi's (1997) feature-based account, however, both English and Spanish fronted topics target the same functional projection. The parametric difference is that, in English, the fronted topic connects to the comment via a null anaphoric operator whereas in Romance this function is realized by a clitic.

To summarize, Although Spanish and English FFs are assumed to be very similar constructions, topicalization and CLLD are constructions that differ in Spanish and English, not so much functionally as morphophonetically (null operator versus clitic), and possibly syntactically as well, if we assume Anagnostopoulou's (1997) analysis. In other words, one can say that there are no unambiguous syntactic diagnostics to distinguish topicalization from FF in English, although in Spanish the presence versus lack of the clitic clearly distinguishes the two. However, and important for our purposes in this article, CLLD and topicalization are functional equivalents, in the sense that both are topic-marking constructions.

\section{CONSTRUCTION FREQUENCY}

Many authors state that CLLD is much more frequent in Spanish oral communication than topicalization is in English (e.g., Kempchinsky 2008). However, it is difficult to come by hard, corpus-based evidence and not just impressionistic or anecdotal data. The available corpora in Spanish and English cannot be easily searched for a specific IS-marking construction, because the ones that are tagged for such information mostly contain written texts. It is important that none of the written corpora contain tagging for intonation, but intonation is one of the most important ways of marking IS, for example, in English. Furthermore, constructions such as CLLD and topicalization are much more common in oral, informal communication, so corpus data for studying them has to come either from oral corpora or from transcribed oral communications, even fiction.

The NOCANDO corpus (Brunetti, Bott, Costa, \& Vallduví, 2011) is specifically created with the aim of studying IS. It contains spontaneous speech: a total of 222 narrations, lasting about $16 \mathrm{hr}$, elicited from 68 native speakers of Catalan, Italian, Spanish, English, and German. ${ }^{3}$ The Spanish part contains about 25,000 words and 3,800 segments. The 13 Spanish speakers, aged 17-29 (mean age $=20$ ), were graduate and undergraduate students in Barcelona, but their L1 
Slabakova: Second language knowledge of the syntax-discourse interface

was Spanish, not Catalan. Data was elicited by asking the speakers to narrate three stories to an experimenter while looking at the pictures of three picture books by Mercer Meyer (Frog Goes to Dinner, A Frog on His Own, and One Frog Too Many). The oral narratives were transcribed and annotated in segments, segments being equal to clauses or verbless phrases. The various noncanonical constructions were then treated as properties of segments. We are interested here in the frequency of CLLD. The Spanish narratives contained 39 CLLDs and LDs (together), which amounted to $1.35 \%$ of all finite clauses. Furthermore, there were 61 clitic doubling constructions, $2.1 \%$ of all finite clauses. ${ }^{4}$ Brunetti (2009) reports that in two oral corpora containing 59,800 words equal to $5 \mathrm{hr}$ of spontaneous speech (the NOCANDO and another oral corpus), 29 FF constructions were found. Although the number of clauses is not reported, extrapolating from the number of words it seems that FF is roughly half as frequent as CLLD in Spanish.

What are the comparative frequencies for English? Birner and Ward (1998) collected a corpus of naturally occurring data of several thousand tokens. Their sources are both written and oral, and include newspapers, magazines, novels, nonfiction books, academic prose, portions of the Brown Corpus, personal conversations, TV shows, films, interviews, and transcripts. Some evidence suggests that topicalization is more characteristic of spoken than of written English, as Ward (1988, p. 96) found in his comparison of the spontaneous speech and written work of Richard Nixon. In Nixon's book Six Crises, there were a total of 69 preposings in 9,719 sentences, for a ratio of 1:140. However, the exact ratio of topicalization and FF tokens to all the sentences in the corpus has not been published.

Gregory and Michaelis (2001) searched 250,000 words from the 2.4 million word Switchboard Telephone Speech Corpus. The data excerpt contained 450 conversations, each with an average of 70 turns per speaker, comprising 72,571 total utterances of all discourse types (including statements, questions, back channels, yes/no answers, etc.). Of this total, 32,805 utterances are clauses (both statements and questions). There were only 44 topicalizations among these finite utterances. To consider whether individual variation is a factor affecting the use of topicalizations, the authors considered age, dialect, and gender of the speakers. None of these factors turned out to be significantly correlated with the use of topicalizations. Another study, Postolache (2005), examined the Wall Street Journal corpus, containing 1,107,392 words, and the novel 1984 by George Orwell, containing 104,136 words. In the Wall Street Journal corpus, Postolache found 24 examples of noncanonical left dislocations, of which 14 were FF and 10 were topicalizations. In the novel 1984, there were 68 such noncanonical constructions, $29 \mathrm{FFs}$, and 29 topicalizations.

Although not directly comparable, the studies whose frequency findings we have reviewed above suggest that Spanish CLLD is much more frequent than English topicalization. CLLD appears 39 times in roughly 3,800 segments of the NOCANDO corpus, or in $1.35 \%$ of all finite clauses. English topicalization appears 44 times in 32,805 finite sentences of the Switchboard Corpus, or in $0.00134 \%$ of sentences. However imperfect our comparison, these two frequencies differ by a factor of 1,000, which is bound to constitute a significant difference. Furthermore, 
Slabakova: Second language knowledge of the syntax-discourse interface

FF seems to be half as frequent as CLLD in Spanish and roughly as frequent as topicalization in English.

\section{L2 ACQUISITION OF LEFT PERIPHERY DISLOCATIONS}

Because IS marking in a L2 has been identified as potentially constituting a challenge to learners owing to its added cognitive and processing complexity, it has attracted the attention of numerous L2 acquisition researchers. Valenzuela (2005, 2006) was the first to investigate CLLD in near-native Spanish. She examined syntactic, pragmatic, and semantic properties of CLLD: sensitivity to syntactic islands, discourse appropriateness, and the specificity constraint (only specific dislocates are clitic doubled but generic ones are not). Valenzuela's near-native learners of Spanish were 100\% accurate in accepting specific CLLDs in the appropriate contexts. However, they were much less accurate on rejecting generic CLLDs. Valenzuela interpreted this finding as near natives having residual difficulties at the syntax-discourse interface. However, Slabakova and Ivanov (2011) argued that, taking into account the native speakers' variable ratings of generic CLLDs and some features of the experimental contexts, the behavior of the near natives actually displayed remarkable sensitivity to discourse.

Ivanov $(2009,2012)$ tested the equivalent construction to CLLD, but in L2 Bulgarian, and again the learners were native speakers of English. Unlike Valenzuela, he contrasted CLLD in topic and focus discourse situations but employed only specific dislocates. The majority of advanced Bulgarian learners in his experiment ( 8 out of 10) evaluated the felicitous sentences significantly higher than the infelicitous sentences. Furthermore, Ivanov showed that syntactic knowledge of clitics is significantly correlated with knowledge of their felicity in discourse.

Donaldson (2011) investigated LDs in the speech and comprehension of nearnative French learners with English as their native language. LDs in English differ from topicalization in that there is a strong pronoun, coreferential with the dislocate, in the argument position (e.g., My wonderful Felix, everyone loves him.). In various syntactic respects, LDs are similar in English and French. However, their discourse functions differ significantly: English LDs most often refer to entities brand new to the discourse, whereas French LDs refer to already evoked entities. Donaldson recorded 10 native speaker-near-native speaker dyads in spontaneous conversation. He reports that the use of LDs by near-native speakers was nativelike and perfectly appropriate. "The near-natives' distribution of unused, inferable, and evoked referents is statistically indistinguishable from that of the natives and shows the native-like preference for evoked referents in LD" (Donaldson, 2011, p. 422). The results of two comprehension tests also confirm this conclusion. Donaldson concludes that the near-native speakers' mastery of LDs challenges the IH.

Bohnacker (2010) investigates marking of topic and focus in L1 German-L2 Swedish interlanguage. Although Swedish and German are both verb second Germanic languages, their use of the left periphery of the sentence differs with respect to IS marking. Although Swedish places the focused material later in the sentence and uses an expletive in the subject position, German can start the 
Slabakova: Second language knowledge of the syntax-discourse interface

sentence with a focused subject. As a result of this topic-focus order, Swedish has disproportionally more expletive-initial sentences. Bohnacker examined the oral and written production of six advanced learners of Swedish. Although the learners did not reach the native percentages of sentence-initial expletive use, there was positive development in the rates of expletive use, suggesting that syntaxpragmatic difficulties can be overcome as proficiency develops.

This necessarily brief overview of research on IS marking indicates that knowledge and correct use of discourse-appropriate strings is attainable in the L2. Three of the authors mentioned in this section (Ivanov, Donaldson, and Bohnacker) have argued explicitly against the $\mathrm{IH}$, using their findings on dislocations to the left periphery. In the present paper, data both supporting and challenging the IH will be presented; I will try to reconcile the findings by evoking other important factors for the success or failure of acquisition at the syntax-discourse interface. Two of those factors are discussed in the next section.

\section{L1 TRANSFER AND INPUT FREQUENCY IN L2 ACQUSITION}

Transfer is acknowledged as the single most important factor in L2 acquisition (papers in Gass \& Selinker, 1993; Schwartz \& Sprouse, 1996; White, 1989). It is relatively uncontroversial that the L2 initial state is either completely (Schwartz \& Sprouse, 1996; White 1989) or partially (Vainikka \& Young-Scholten, 1996) a replication of the native grammar. As mentioned above, residual L1 effects can be expected at the syntax-discourse interface even for near-native L2 speakers (Sorace, 2005; Sorace \& Filiaci, 2006). The effects of the native language are clearly visible in the studies of Hopp (2009), Ivanov (2102), and Bohnacker (2010) reviewed above. Recently, the pertinent research question with respect to L1 transfer has been not so much whether transfer can be attested but whether L1 transfer can be overcome in successful acquisition.

As in usage-based accounts, the primary linguistic data has always been recognized as crucial in setting parameter values within the generative framework (together with innately provided parametric options). There has recently been a new and welcome impetus toward a formal treatment of synchronic variation in the input, both in language production (Kroch, 2001) and in L1 acquisition (Crain \& Pietroski, 2002; Roeper, 2000). Charles Yang's variational learning model, which unifies parameter setting with general learning mechanisms based on frequency of parametric evidence in the input, is gaining theoretical and empirical support (Yang 2002, 2004, 2010). The main idea of this model is that parameters are indispensable in constraining the hypothesis space of the child, but a parameter supported with abundant and unambiguous evidence in the input will be learned earlier than a parameter for which the supporting evidence is scarce or less reliable.

In L2 acquisition theory, emergentist, connectionist, and usage-based theories place input frequency at the heart of development explanation (e.g., Ellis, 2002, 2006). ${ }^{5}$ These theories argue that the acquisition of language is exemplar-based and emerges from experience. Grammar can be learned from the input using domaingeneral mechanisms. Grammar acquisition comprises the learning of various constructions (in random order) based on analogy and frequency-biased abstraction over regularities within the constructions. Although there is compelling evidence 
for the effects of frequency in L2 acquisition (see, e.g., Collins, Trofimovich, White, Cardoso, \& Horst, 2009), there are many grammatical properties and constructions where L2 acquisition appears to develop along its own course and at its own rate, regardless of input frequency (Gass \& Mackey, 2002). Furthermore, there are areas of the grammar (such as semantics) where input is rare, nonexistent, or misleading but acquisition appears to proceed unimpeded (Slabakova, 2006). For our purposes in this study, it is imperative to heed O'Grady, Lee, and Kwak's (2009, p. 72) warning that "[i]n considering the role of input frequency in language acquisition (first or second), it is vital to bear in mind a key point: what counts is not how many times learners hear a particular form-it is how many times they encounter mappings between a form and its meaning." This warning takes on particular importance when we look at acceptability evaluation in an extended discourse context. The reader should keep in mind that all the constructions we test in this study are perfectly grammatical on their own, and it is only in the extended context (at least two to three sentences) that their acceptability or unacceptability can be judged. Thus when we inspect "frequency of a construction in the input to learners," in this particular case we mean "frequency in the appropriate context."

\section{LEARNING TASKS AND PREDICTIONS FOR ACQUISITION IN THE TWO DIRECTIONS}

The substance of the learning tasks depends on the specific analysis of topicalization that is espoused. Because the findings of the studies I report on should be explainable by all proposed analyses, I will start by spelling out the predictions of the four theoretical analyses outlined above. On movement approaches to topicalization, for example, Rizzi's (1997) analysis within the cartographic approach, English and Spanish topicalizations essentially represent the same feature-driven movement, and they differ only in the presence or absence of a clitic close to the verb; hence this is the new information that learners have to acquire. The learning tasks would be similar in the two learning directions under Lopéz' (2009) pragmatic features approach as well, again modulo the acquisition of the clitic doubling. Under the approach where topicalization is not feature driven but is a pure interface phenomenon, the movement of the displaced constituent applies optionally and manifests multiple possible landing sites (Neeleman \& van de Koot, 2008; Neeleman et al., 2009). However, because this analysis is impossible to demonstrate and check with the monoclausal Spanish and English sentences we look at, the predictions of this approach as to learning difficulty remain the same. The only linguistic analysis positing more than clitic presence or absence differences between English and Spanish topicalization is Anagnostopoulou (1997). She posits a base-generation analysis where the English and Spanish left-dislocated constituents adjoin different functional projections while being associated with operator-variable chains: CP in English and inflection phrases in Spanish. However, the clitic and the null operator have similar operator properties; hence, the learning task is somewhat superficial and is restricted to learning the surface reflex (clitic or null morpheme) of the operator. Recall, however, that we are not testing syntactic differences that can fall out of the different adjunction sites of the dislocates in Spanish and English. ${ }^{6}$ 
Slabakova: Second language knowledge of the syntax-discourse interface

In sum, I have outlined the learning tasks for the two directions of acquisition (Spanish to English and English to Spanish) under four syntactic and pragmatic approaches to topicalization in the two languages. Although quite diverse in their theoretical underpinnings, the four theoretical approaches make essentially similar predictions as to learning challenges: neither of the learning directions will present more difficulties to learners compared to the other, because the syntactic and pragmatic mechanisms underlying topic marking are similar in the two languages. For all of these approaches, the monoclausal topic marking sentences in appropriate context that we examine in this article involve learning the surface presence of a clitic versus a null operator.

As discussed in the previous section, however, the predictions based on the frequency of the construction in the input to learners, hence based on the evidence that the learners encounter in the input, are very different. The input-based predictions point to much easier acquisition of CLLD and FF in Spanish L2, and much more difficult acquisition of topicalization and FF in English L2. The IH predicts similar and difficult acquisition of both topicalization/CLLD and FF in both learning directions. Finally, L1 transfer predicts difficulties in topicalization/CLLD but superior accuracy in FF, because the latter construction is (superficially) similar in Spanish and English whereas the former is morphophonologically different. A summary of these predictions and the results are presented later in the article.

\section{STUDY 1: L2 ACQUISITION OF SPANISH CLLD}

In this section, I report on partial results from a bigger study on the L2 acquisition of Spanish CLLD, clitic right dislocation (CLRD), FF, and rheme, using Lopéz' (2009) pragmatic feature approach (Slabakova et al., 2012; Slabakova, Rothman, \& Kempchinsky, 2011). This section summarizes results from Slabakova et al. (2012). The study's goal was to test acquisition predictions based on the two pragmatic features that Lopéz (2009) proposes, [ \pm anaphor] and [ \pm contrast], as well as an additional semantic contrast within CLLD but missing in CLRD. The semantic contrast means that in the CLLD construction, the dislocate and the antecedent can be in a semantically loose relationship, whereas in CLRD they have to be identical. For the purposes of the comparison in this article, the data from the original study were analyzed in a different way. The CLLD condition in this data set includes test sentences where the antecedent and dislocate are identical as well as sentences in which they are in a superset-set relationship. This was possible because in the original study (see Slabakova et al., 2012, their tables 4-6), the semantic distinction did not play any role in the acceptance or rejection of the test sentences with and without clitics.

Eighty-eight participants took a battery of tests, posted on WebSurveyor, an independent online survey platform. Twenty-one were native speakers of Spanish from different Spanish-speaking countries (1 from Argentina, 4 from Chile, 4 from Colombia, 1 from Costa Rica, 2 from Cuba, 3 from Spain, 5 from Mexico, and 1 from Venezuela); 67 were adult learners of Spanish. The learners and the native speakers started the test with an anonymous questionnaire probing for 
Slabakova: Second language knowledge of the syntax-discourse interface

Table 1. Biographical data of participants in Study 1

\begin{tabular}{lccc}
\hline \hline & & & Average Age at \\
& Average Age & Women/Men & \begin{tabular}{c} 
Start of Spanish \\
\hline Native speakers $(n=21)$
\end{tabular} \\
Near natives $(n=22)$ & 35.8 & $13 / 8$ & 0 \\
Advanced $(n=22)$ & 27.9 & $11 / 11$ & 12.3 \\
Intermediate $(n=23)$ & 22.3 & $10 / 12$ & 11.4 \\
\hline \hline
\end{tabular}

demographic information and age of acquisition of Spanish. Table 1 summarizes that information.

The learners were divided into proficiency groups based on the DELE, the official exam of proficiency administered by the Spanish Ministry of Education. The test contained 50 items distributed between a cloze test format and a multiplechoice format. The near-native range for this test was set at 47 to 50 , the advanced participants scored between 40 and 46, and the intermediate participants had a much wider range of 20 to 39. Means and standard derivations on the proficiency test are compared with those of Study 2.

The battery of tests crucially included a test of syntactic knowledge of clitics. This test included 10 multiple-choice sentences with five answers each. More than one answer was possibly correct for each sentence (see example from this test below).

(5) Dulce: ¿Te gustó algo de la tienda?

"Did you like something from the store?"

Julia: Me encanta esa chaqueta,

CL charm this jacket, pronto.

"I love this jacket, soon

$\square$ me quiero comprarla

$\square$ me la quiero comprar

$\square$ quiero comprármela

$\square$ quiero comprar

$\square$ quiero me la comprar

One point was given for choosing a correct option and for not choosing an incorrect option. Thus the overall accuracy score on the clitic test was also out of 50 . The cutoff point of 35 , or $70 \%$, was used to select learners whose performance on the acceptability test would be further considered.

The main test of the study was an acceptability judgment task of sentences with and without clitics in appropriate context. Each test sentence string was grammatical with and without a clitic; however, the variant with a clitic (CLLD) was only appropriate in topic contexts, while the variant without a clitic would be felicitous in focus contexts. Intonation is also very important for classifying a sentence as topic or focus, and that is why the context stories and the test sentences 
Slabakova: Second language knowledge of the syntax-discourse interface

were presented both written and orally with natural intonation by native speakers. Figure 1 offers a screen shot of the experimental presentation.

Each test item had the following structure: after a brief context, a short dialogue was presented that contained two possible answers, our test sentences. Each one of the answers had to be evaluated for felicity, on a scale of 4 (perfect) to 1 (very strange), but participants could also choose "I don't know." Within each screen (context-dialogue combination), there were two answers to judge: one with a clitic and one without a clitic (see screenshot). In the end, 20 evaluation scores for the CLLD condition were obtained. In the $5 \mathrm{FF}$ contexts, participants had to evaluate one sentence with clitic (unacceptable) and one without clitic (acceptable). ${ }^{7}$

Figure 1 contains an example of FF, and we offer an example of a CLLD test item with identity between dislocate and antecedent below. Notice that the context both in Figure 1 and in (6) justify a contrastive interpretation of the test sentences; however, the FF context imposes a correction interpretation, while the CLLD context allows the contrasting of two already mentioned constituents, hence topics.

(6) Mónica decidió quedarse en casa preparando la cena mientras su esposo Juan fue al supermercado. Cuando regresaba a casa, Juan recibió una llamada teléfonica de Mónica, quien quería asegurarse de que Juan había comprado lo que necesitaba para preparar la ensalada.

Monica decided to stay at home making dinner while her husband Juan went to the supermarket. When he was on the way home, Juan received a call from Monica, who wanted to make sure that Juan had bought everything she needed.

Mónica: Entonces ¿compraste el aceite de oliva y el vinagre?

Monica: So, did you buy the olive oil and the vinegar?

(A) Juan: El vinagre lo compré. Tenemos aceite en la casa.

The vinegar it I bought. I know we have oil at home.

(B) Juan: \#El vinagre compré. Tenemos aceite en la casa.

The vinegar I bought. I know we have oil at home.

We will compare the CLLD and the FF results next. Figure 2 and Figure 3 offer the mean ratings, as well as a visual presentation of these means.

A general linear model analysis of variance was conducted to compare the ratings of the participants. Condition (CLLD or FF) and acceptability (acceptable or unacceptable) were used as within-participant variables; group (native, near native, advanced, or intermediate) was the between-participants variable. There was an effect of condition, $F(1,84)=27.039, p<.0001$, an effect of acceptability, $F(1,84)=150.193, p<.0001$, an effect of group, $F(3,84)=4.376$, $p=.007$, and a significant interaction between acceptability and group, $F(3$, $84)=11.390, p<.0001$. The interactions between condition and group, condition and acceptability, as well as the three-way Condition $\times$ Acceptability $\times$ Group interaction were not significant. Post hoc comparisons showed that the there were no statistical differences between the ratings of native and near-native speakers ( $p=.150)$, but the advanced and the intermediate learners' behavior differed.

The important measure relevant to the research question was a significant contrast between ratings to acceptable and unacceptable test sentences within the 


\section{Estudio lingüístico}

1) Juan y Mónica invitaron a María a comer. La cena se sirvió en la terraza y todo estaba muy rico. María felicitó a Juan por la sopa que había hecho. Cuando Mónica escucha esto, responde:

1. 1

Mónica: La carne la preparó Juan, no la sopa. (Recuerde presionar el botón "play")

4. $\bullet$ O

$\bigcirc 4$ (perfecta) $\bigcirc 3 \bigcirc 2 \bigcirc 1$ (muy extraña) $\bigcirc$ No sé

2) Mónica: La carne preparó Juan, no la sopa. (Recuerde presionar el botón "play")

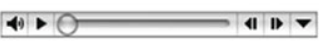

$\bigcirc 4$ (perfecta) $\bigcirc 3 \bigcirc 2 \bigcirc 1$ (muy extraña) $\bigcirc$ No sé

Previous Page Next Page (2 of 47)

This online survey is powered by WebSurveyor.

Figure 1. (Color online) The experimental presentation in Study 1. 
Slabakova: Second language knowledge of the syntax-discourse interface

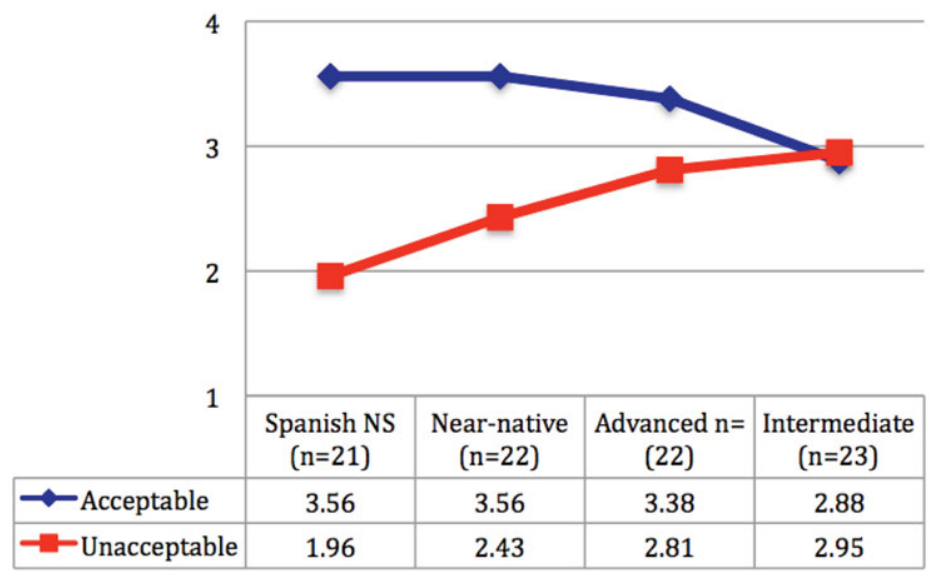

Figure 2. (Color online) The mean ratings of experimental groups on CLLD (range $=1-4)$.

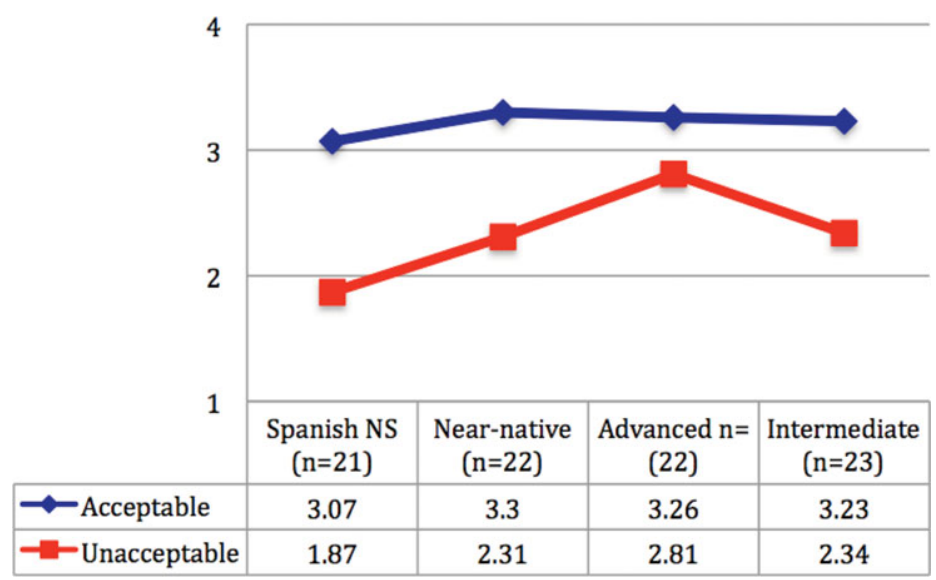

Figure 3. (Color online) The mean ratings of experimental groups on fronted focus (range $=$ $1-4)$.

same group of participants. With this design, we are interested in finding whether participants treated the two test sentences differently, embedded in the same topic or focus context. Pairwise comparisons between felicitous versus nonfelicitous sentences within the ratings of each participant group were further inspected. The results of those comparisons are presented in Table 2. As the results indicate, the native speakers demonstrate a significant contrast between acceptable and unacceptable sentences, both on the CLLD and the FF constrictions. All learner groups with the exception of the intermediate learners also securely distinguish sentences with clitics (acceptable) and without clitics (unacceptable) in the CLLD 
Slabakova: Second language knowledge of the syntax-discourse interface

Table 2. Paired samples statistics on contrasts of acceptability for participant groups in Study 1

Contrast Between Acceptable and Unacceptable

CLLD Sentences $\quad$ FF Sentences

\begin{tabular}{lll}
\hline Native speakers $(n=21)$ & $t=13.534, p<.0001$ & $t=7.297, p<.0001$ \\
Near natives $(n=22)$ & $t=5.235, p<.0001$ & $t=4.039, p=.001$ \\
Advanced $(n=22)$ & $t=2.534, p=.033$ & $t=2.005, p=.058^{a}$ \\
Intermediate $(n=23)$ & $t=-0.280, p=.782^{b}$ & $t=3.231, p=.004$ \\
\hline \hline
\end{tabular}

Note: CLLD, clitic left dislocation; FF, fronted focus.

${ }^{a}$ This $p$ value approaches significance.

${ }^{b}$ Nonsignificant.

condition. On FF, where knowledge can be transferred from the native language, all groups demonstrate a significant contrast, with the exception of the advanced group, whose results approach significance.

In summary, the findings in the English to Spanish learning direction indicate that the near-native and the advanced groups of learners have acquired the Spanish requirement that topic dislocates have to be clitic doubled. The mean ratings of the near-native speakers are not significantly different from those of the native speakers. In order to be accurate on this construction, learners of Spanish with English as their native language need to substitute a null operator with an overt clitic operator, but otherwise no major restructuring of the grammar is necessary, according to the majority of analyses in the literature. Thus so far the results confirm the underlying similarity of CLLD and topicalization, and challenge the IH. Such conclusions, however, turn out to be premature, as we will see in the next section.

\section{STUDY 2: L2 ACQUISITION OF ENGLISH TOPICALIZATION}

The comparison between English topicalization and FF in the acquisition of English as a L2 by Spanish native speakers comes from a bigger study on third language acquisition involving Basque-Spanish-English learners and SpanishBasque-English learners (Slabakova \& García Mayo, 2012). That study included a big group of English L2 participants. The research design of Study 2 was very similar to Study 1; the constructions investigated were topicalization, FF, and LD, where a pronoun picks out the referent of the dislocate (e.g., My wonderful Felix, everyone likes him). One significant difference was the utilization of a larger rating scale, 1 to 7 instead of 1 to 4 . In other respects, the main tests of the two studies were identical. The topicalization examples included tokens in which the antecedent and the dislocate were identical, as well as tokens in which they were in a superset-set relationship. The test items were presented aurally and visually; they were recorded by native speakers using natural intonation. Participants had to rate the test sentences (by clicking on a radio button) from 1 (not natural in 
Slabakova: Second language knowledge of the syntax-discourse interface

the context) to 7 (perfectly natural), with a separate option for I don't know. A screenshot appears in Figure 4. The participants were asked to take the test at one sitting and not to go back and change their answers. Some participants were remunerated for their time; others volunteered.

Ninety-six participants' performance will be reported on here. See Table 3 for demographic data. The control group consisted of 24 American native speakers, residing mainly in Iowa. The Spanish native speakers, who were residing in Spain and hence were speakers of peninsular Spanish, were divided into proficiency groups on the basis of a standardized English test, employing a cloze format with three choices for each blank. There were 50 items in this test. The intermediate group scored on average 34.04 , with a range of 25-39 $(n=23)$. Participants scoring between 40 and 45, with a mean of 43.03, were classified as advanced learners $(n=30)$. Learners who scored between 46 and 50 on the proficiency test, with a mean of 47.89 , were deemed to be near native $(n=19)$. Thus the proficiency groups of Study 2 closely mirror the groups in Study 1, with the exception that the intermediate learners in the Spanish L2 study have a lower mean and a higher standard deviation as compared to the English L2 study. Thus, it is possible that the intermediate English L2 group may be of higher proficiency. However, keep in mind that the two proficiency tests are not immediately comparable (Table 4). ${ }^{8}$ Although the tests are not directly comparable, it seems safe to assume that at least the two advanced and the two near-native groups were of equal proficiency. The majority of participants in those groups were advanced graduate students and teaching assistants of language and literature in a university setting. All Spanish-native participants in the advanced and near-native groups reported extended stays in an English-speaking country and using the language in professional meetings. Some individuals reported having obtained $\mathrm{PhD}$ degrees from American or British universities. All-English native participants also spent extended periods in Spanish-speaking countries and visited repeatedly, although they did not report advanced degrees from a Spanish-language university.

The acceptability judgment task consisted of 30 items. Each item in turn contained a short context and two dialogues; the first sentence in each dialogue was the immediate context, and the second one was the test sentence. The test items closely mirrored published LDs from the literature. Figure 4 gives an example test item from the topicalization construction; in this one the antecedent is the superset (the fish) and the dislocate is the set (the salmon). See an example from the FF condition in (7).

(7) Greg and Susan are at the mall. They have argued a lot today and, as usual, Greg contradicts everything Susan says. They come across their friend Mitchell, who has bought a couple of things. To start the conversation, Susan says:

Susan: That looks like a nice shirt that you bought, Mitchell.

Greg: A JACKET he bought, not a shirt.

$\leftarrow$ acceptable

Susan: That looks like a nice shirt that you bought, Mitchell.

Greg: A JACKET he bought it, not a shirt.

$\leftarrow$ unacceptable 
1. John and his sister Sophie are in a Japanese restaurant. John has never eaten in this restaurant before, so he is not sure about what to order. He decides to ask Sophie:

John: Have you tried the fish here?

Sophie: Last week I had the sole. It was delicious. The salmon I haven't tried it yet.

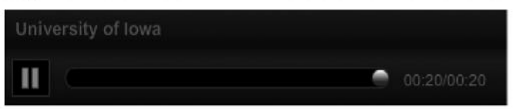

\begin{tabular}{|c|c|c|c|c|c|c|c|}
\hline \multirow{2}{*}{$\begin{array}{c}\text { Not natural } \\
1\end{array}$} & \multirow[b]{2}{*}{2} & \multirow[b]{2}{*}{3} & \multirow[b]{2}{*}{4} & & \multicolumn{3}{|c|}{ Perfectly natural } \\
\hline & & & & 5 & 6 & 7 & I don't know \\
\hline 0 & 0 & 0 & 0 & 0 & 0 & 0 & 0 \\
\hline
\end{tabular}

John: Have you tried the fish here?

Sophie: Last week I had the sole. It was delicious. The salmon I haven't tried yet.

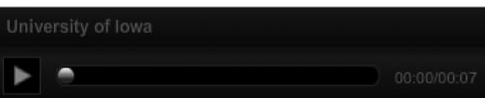

Not natural

3

$\bigcirc$

(

○

Perfectly natural

$\begin{array}{cc}7 & \text { Idon't know } \\ 0 & \bigcirc\end{array}$

Figure 4. A screen shot of test item presentation in Study 2. 
Slabakova: Second language knowledge of the syntax-discourse interface

Table 3. Biographical data of participants in Study 2

\begin{tabular}{lccc}
\hline \hline & & & Average Age at \\
& Average Age & Women/Men & \begin{tabular}{c} 
Start of English \\
\hline Native speakers $(n=24)$
\end{tabular} \\
Near natives $(n=19)$ & 25.3 & $20 / 4$ & 0 \\
Advanced $(n=30)$ & 25.8 & $13 / 6$ & 11.5 \\
Intermediate $(n=23)$ & 24.9 & $22 / 8$ & 10.4 \\
\hline \hline
\end{tabular}

Table 4. Comparison of proficiency test results

\begin{tabular}{lcccccccc}
\hline \hline & \multicolumn{2}{c}{ Spanish L2 Study } & & \multicolumn{3}{c}{ English L2 Study } \\
\cline { 2 - 3 } & Range & Mean & $S D$ & & Range & Mean & $S D$ \\
\hline Near natives & $47-50$ & 47.86 & 0.88 & & $46-50$ & 47.89 & 1.28 \\
Advanced & $40-46$ & 42.95 & 2.01 & & $40-45$ & 43.03 & 1.71 \\
Intermediate & $20-39$ & 29.35 & 5.77 & & $25-39$ & 34.04 & 4.33 \\
\hline \hline
\end{tabular}

Note: L2, second language.

Because English lacks clitics, for all conditions, the two test sentences embedded in the context had either a pronoun or a null copy of the moved dislocate. Note that the test as a whole did contain sentences in which a pronoun was acceptable, and these were the LD test items; however, the contexts of the topicalization, FF, and LD conditions were different. There were six topicalization sentences, six LD sentences, and six FF sentences interspersed with 12 fillers, half of which also contained object pronouns. I will only report on the topicalization and FF test items here. Again, as in Study 2, a choice had to be made whether to present two test sentences under the same story or to present each context story with only one dialogue underneath it. While the second presentation would have been ideal, the first one was chosen (see examples above) for the following reasons. First, single-sentence presentation would have doubled the length of the test to more than an hour, which was deemed unacceptable. The test would have become too taxing and tiring for the participants due to its length. Second, the story is only the general context needed for the understanding of the dialogue, but in each dialogue the first sentence is the immediate context of the test sentence, and that was repeated twice, before each test sentence. Third, a comparison between Study 1 and Study 2 would have become more precarious if the two had different presentation designs. Figure 5 and Figure 6 present the mean ratings and visualizations of them.

A general linear model analysis of variance was conducted to compare the ratings of the various participant groups. Condition (topicalization or FF) and acceptability (acceptable or unacceptable) were the within-participant variables; group (native, near native, advanced, or intermediate) was the betweenparticipants variable. There was an effect of condition, $F(1,92)=33.738$, 
Slabakova: Second language knowledge of the syntax-discourse interface

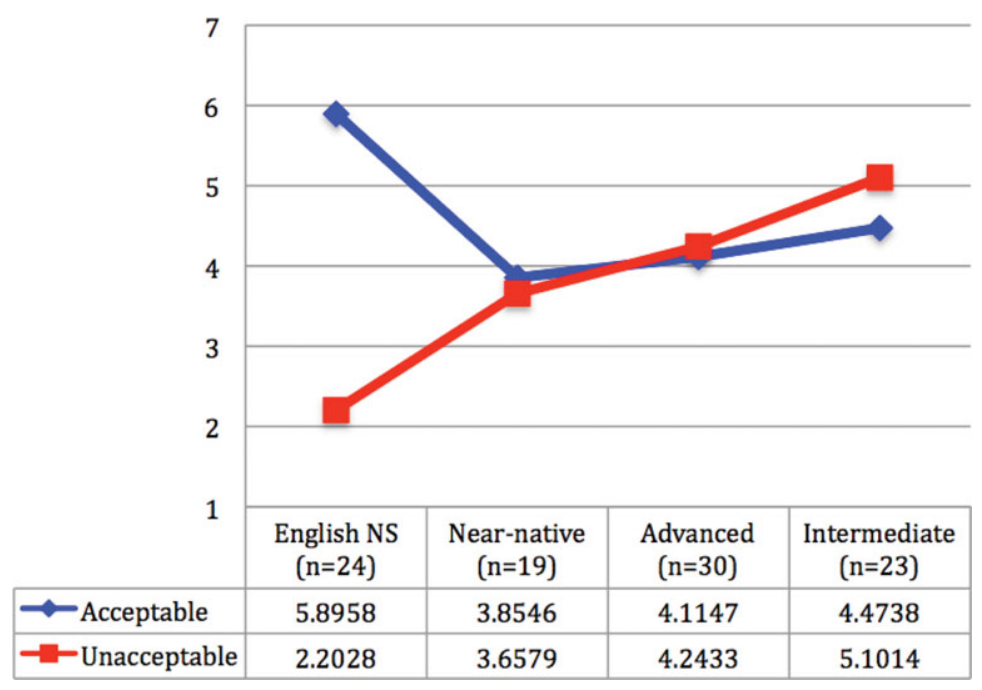

Figure 5. (Color online) The mean ratings of experimental groups on topicalization (range $=$ $1-7)$.

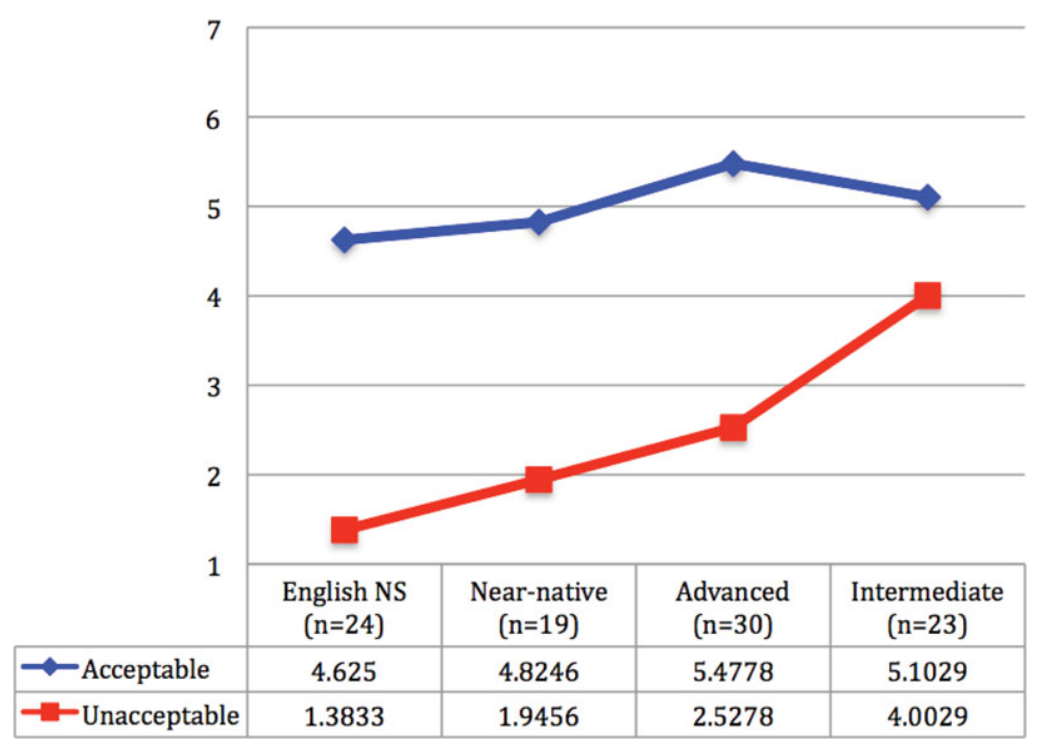

Figure 6. (Color online) The mean ratings of experimental groups on fronted focus (range $=$ $1-7)$.

$p<.0001$, an effect of acceptability, $F(1,92)=237.744, p<.0001$, and an effect of group, $F(3,92)=12.680, p<.001$. The significant interactions were between condition and group, $F(3,92)=6.876, p<.0001$, acceptability and group, $F(3,92)=38.969, p<.0001$, condition and acceptability, $F(1,92)=99.110$, 
Slabakova: Second language knowledge of the syntax-discourse interface

Table 5. Paired samples statistics on contrasts of acceptability for participant groups in Study 2

\begin{tabular}{|c|c|c|}
\hline & \multicolumn{2}{|c|}{ Contrast Between Acceptable and Unacceptable } \\
\hline & Topicalization Sentences & FF Sentences \\
\hline Native speakers $(n=24)$ & $t=11.120, p<.0001$ & $t=10.627, p<.0001$ \\
\hline Near natives $(n=19)$ & $t=1.102, p=.285^{a}$ & $t=8.255, p<.0001$ \\
\hline Advanced $(n=30)$ & $t=-0.754, p=.457^{a}$ & $t=10.282, p<.0001$ \\
\hline Intermediate $(n=23)$ & $t=-4.534, p<.0001^{b}$ & $t=3.114, p=.005$ \\
\hline
\end{tabular}

Note: FF, fronted focus.

${ }^{a}$ Nonsignificant.

${ }^{b}$ This statistical difference is in the wrong direction.

$p<.0001$, and condition, acceptability, and group, $F(3,92)=21.187, p<.0001$. The post hoc comparisons revealed that there were no statistical differences between the ratings of native and near-native speakers $(p=1)$; the advanced and the intermediate learners' behavior was different from the natives'.

As the contrasts in Table 5 illustrate, all learner groups were highly accurate in distinguishing between acceptable and unacceptable sentences in the FF condition. At the same time, none of the learner groups demonstrated a contrast between acceptable and unacceptable topicalization in English. Note also that the ratings of the near-native and the advanced learners on topicalization sentences with and without a pronoun tend to cling to the middle ground, 4 being equidistant from 1 and 7. Thus, this behavior (of groups of possibly similar proficiency) is in stark contrast to the learner performance in the Spanish L2 study.

\section{DISCUSSION}

We are now in a position to revisit our predictions of ease or difficulty of L2 acquisition in two learning directions. Recall that the four linguistic analyses we described predict that English natives learning CLLD in Spanish and Spanish natives learning topicalization in English would be faced with a learning task of relative similarity. Three of the four analyses postulate that the only syntactic difference between English and Spanish discourse-conditioned movements has to do with the overt versus null character of the copy of A-bar movement. Because syntactic knowledge of clitics was a condition on inclusion of participants in Study 1, we should not expect any major difficulties to come from lack of familiarity with clitic functions or placement in the interlanguage grammars of the Spanish L2 learners. In the other direction, pronouns were not deemed to present a challenge because both English and Spanish have strong pronouns. The expectations based on functional equivalence and (roughly) equal linguistic complexity were not supported. Studies 1 and 2, which employed very similar methodology, showed that learning English topicalization is much more difficult than learning Spanish CLLD. None of the English L2 learner groups, including 
Slabakova: Second language knowledge of the syntax-discourse interface

Table 6. Summary of predictions and actual results

\begin{tabular}{lcccc}
\hline \hline & $\begin{array}{c}\text { Interface } \\
\text { Hypothesis }\end{array}$ & $\begin{array}{c}\text { L1 } \\
\text { Transfer }\end{array}$ & $\begin{array}{c}\text { Input } \\
\text { Frequency }\end{array}$ & $\begin{array}{c}\text { Advanced and } \\
\text { Near-Native L2er Result }\end{array}$ \\
\hline Topicalization in English & Hard & Hard & Hard & Failure \\
CLLD in Spanish & Hard & Hard & Easy & Success \\
FF in English & Hard & Easy & Hard & Success \\
FF in Spanish & Hard & Easy & Easy $^{a}$ & Success \\
\hline \hline
\end{tabular}

Note: L1, first language; L2er, second language learner; CLLD, clitic left dislocation; $\mathrm{FF}$, fronted focus.

${ }^{a}$ Note that FF is half as frequent as CLLD in Spanish (Brunetti, 2009).

the near-native group, demonstrated a significant contrast between acceptable and unacceptable topicalization sentences. In contrast, the near-native and the advanced learners in the Spanish L2 study had successfully acquired the CLLD and its discourse requirements, although the intermediate proficiency learners had not yet acquired it. Clearly the development of topic marking in the two languages under discussion has different rates of acquisition, which is not predicted by the theoretical descriptions of LDs.

Table 6 is intended to make abundantly clear the predictions of the various L2 acquisition factors and hypotheses, as well as the actual results. The three factors that could have influenced the success or failure of LD acquisition by the advanced and near-native learners are the constructions' discourse dependence, L1 transfer, and diverging frequency in the input to the learners. These factors, the predictions they make, and the actual results are discussed in more detail below.

Because topicalization and FF are constructions at the syntax-discourse interface, the IH predicts that in either of these learning directions, the processing costs of bilingualism may take its toll and even near-native participants might not perform similarly to the native speakers. Residual optionality on both similar and dissimilar constructions could be anticipated owing to processing difficulties at the syntax-discourse interface. However, this was not the case in the interlanguage grammars the findings established. Near-natives and advanced learners performed perfectly on the similar construction (FF), with the near natives not significantly different from native speakers. On the construction where transfer was misleading, topicalization, near-native and advanced participants were able to overcome native transfer, although they did so only in one learning direction. Taken together, these results challenge the IH.

Let us look more carefully into the transfer from the native language issue next. As mentioned above, the Spanish and English LDs tested in these studies differ with respect to whether or not transfer from the native language is helpful or not. Transfer is beneficial to learners for the FF construction in both directions, because the left-dislocated constituent is not clitic doubled in Spanish, making FF (superficially and functionally) similar in Spanish and English. Transfer, however, is misleading in the CLLD/topicalization constructions, because the former employs clitic doubling while the latter does not. Thus, based on transfer alone, we would 
Slabakova: Second language knowledge of the syntax-discourse interface

expect learners to do better on FF than on topicalizations, both in the Spanish $\rightarrow$ English and in the English $\rightarrow$ Spanish directions. However, this is not what we find. Learners do perform very well on FF, but they also manage to overcome transfer in one of the learning directions, the English $\rightarrow$ Spanish direction. It seems that native transfer is taking place, but transfer is not sufficient as the only explanation of the findings.

Finally, considering the different construction frequency of CLLD and topicalization in the input available to learners, it was predicted that Spanish CLLD will be acquired much more easily than English topicalization. According to oral corpora counts reviewed in this article, CLLD is very frequent in vernacular Spanish of all varieties and is many multiples more frequent than topicalization. Of course, we have to distinguish between frequency and acceptability. In this respect, topicalization is perfectly acceptable, although rare. This is supported by the mean acceptability rating that English native speakers gave the examples in our test: 5.89 out of 7. However, that acceptability did not translate into successful acquisition for the learner groups. Frequency seems to trump acceptability. Advanced and near-native learners rated sentences such as The salmon, I haven't tried yet and The salmon I haven't tried it yet with scores around 4 in a range of 1 to 7 , thereby signaling that they didn't really know what to do with this construction. ${ }^{9}$ The intermediate learners find both sentences with clitics and without clitics rather acceptable. This is of course a spectacular contrast with the acquisition of CLLD in L2 Spanish. Although perfectly acceptable to English native speakers, I submit that topicalization is proving impossible to learn for Spanish native speakers at all levels of proficiency because they do not encounter this construction often enough.

Is there any one prediction that is singly capable of explaining all the results? There really is not, as Table 6 illustrates. The predictions of the IH were not directly supported. This hypothesis predicted difficulties in both learning directions, but we found difficulties in only one direction. Transfer from the native language played a critical role, in the sense that it allowed all the English L2 learners to be accurate on FF, but it does not account for the successful acquisition of Spanish CLLD. The predictions of differential difficulty based on different construction frequency go a long way toward explaining our findings. However, taken in isolation, they also come short because FF was acquired successfully, while it is as rare in the input as is topicalization. We must conclude that native transfer together with experience can account for all our findings in their complexity.

The issue of the interplay between the innate language endowment (universal grammar), L1 transfer, and input frequency is the crucial issue in explaining these results. I offer some speculative remarks here on what this interplay might be. Notice that the involvement of universal grammar is moot for this particular construction (topic marking), because the only difference in Spanish versus English representation seems to be the overt or covert nature of the copy of A-bar movement, a morphophonological reflex. With respect to the interplay of L1 transfer and input frequency, an anonymous reviewer proposes that low-frequency constructions might trigger transfer while (relatively) higher frequency constructions do not. In other words, when positive evidence is not copious or fully available, then learners compensate for that by calling on L1 transfer because there is no other possible option. ${ }^{10}$ As discussed above, $\mathrm{L} 1$ transfer is the only process in L2 
acquisition undisputed by both emergentist and innatist approaches, and it obtains right from the L2 initial state. Thus, it is somewhat surprising to conceive of it as a "last-resort" process with very advanced learners. It could also be surmised that a much simpler surface similarity is at play: if the constructions are the same in the two languages, they do not pose a problem to learners. If the constructions are not the same and transfer is misleading, only then frequency becomes a factor. Teasing apart the primacy of transfer or frequency certainly merits further research.

To reiterate, in the case of topicalization, just encountering dislocated constructions (with and without clitics/pronouns) is not sufficient for acquisition: the learner needs to observe and evaluate the wider context and the construction's function within that context. English input could also be misleading to the L2 learner. The language contains the so-called LD construction, where a noun phrase not previously mentioned in the discourse appears dislocated from the main clause, and is referred to by a pronoun in the main clause. Birner and Ward (2004, pp. 162-163) argue that LD and topicalization (what they call preposing) are not functionally similar (see their example 21c as shown below), but it is easy to see how these constructions can be confusing for learners to tease apart.

(8) That woman you were just talking to, I don't know where she went.

Of course, for Spanish learners of English, L1 transfer will be helpful in the case of LD, similar to FF. Teasing apart LD from topicalization in Spanish-English interlanguage is left for further research.

\section{CONCLUSIONS}

The comparison between the findings of Studies 1 and 2 reported on in this article has a number of important implications. First, the contrasting results on the acquisition of a similar linguistic phenomenon in two learning directions suggest that explanations in L2 acquisition have to include diverse factors relating to competence, processing difficulty, as well as experience.

Second, from the point of view of these findings, the syntax-discourse interface doesn't look quite so special as the IH has proposed. With respect to discourse-conditioned LDs, the native language exerts as much influence as in acquiring narrow syntactic, lexicon-syntax, morphology-syntax, or any other interface properties. We have also seen that it is possible to overcome the unhelpful, deceptive transfer from the native language but only with enough experience, based on ample and unambiguous linguistic input. Without sufficient evidence for a certain L2 property, misleading transfer remains unchallenged.

\section{NOTES}

1. Although there is a lot of disagreement in the literature, both topics and foci have been proposed to be possibly contrastive (Büring, 2003; Jackendoff, 1972). "Constituents that are contrastive are understood to belong to a contextually given set out of which 
Slabakova: Second language knowledge of the syntax-discourse interface

they are selected to the exclusion of at least some other members of the set.... In English, contrastive topics and foci are marked by a special intonation" (Neeleman et al., 2009, p. 16).

2. This approach avoids the oft-cited problem of the feature-based analyses (Rizzi, 1997), which have to assign focus and topic features to lexical items (not phrases) in the numeration, before it is known which lexical items would need such features in the discourse.

3. The taxonomy and count of noncanonical constructions in the two Germanic languages has not been published yet.

4. An example of clitic-doubling construction from the corpus is given by the following:

(i) Entonces la tortuga lo ve y se lo dice al NIÑO.

so the turtle it.cl sees and to-him.cl it.cl says to-the boy

"So the turtle sees what happened and tells the boy everything."

5. For extensive discussion, see articles in Applied Linguistics, 2006, 27(4); the Modern Language Journal, 2009, 93(3); and Studies in Second Language Acquisition, 2002, 24(2). For L1 acquisition, see the special issue of Lingua, 2010, 120(11). For a debate between emergentist and nativist perspectives to acquisition, see Lingua, 2008, 118(4).

6. To my knowledge, Valenzuela (2005) is the only study that tests the predictions of Anagnostopoulou's (1997) analysis.

7. An experimental presentation was piloted on native speakers where each context was followed by one test sentence. However, this presentation was abandoned because the native speakers accepted cliticless sentences in topic contexts, more often than not mentally supplying the clitic and not noticing its absence. When two contrasting sentences were presented together on the same screen, the rejection of cliticless CLLD improved dramatically.

8. Given the "mirror image" design of this study, it would have been ideal to have used a standardized, Common European Framework of Reference for Languages based placement test so that each level of the learners would be comparable in both L2s.

9. Note that these results confirm our contention that Spanish speakers will map native clitics onto pronouns in L2 topicalization.

10. I am very grateful to two anonymous reviewers for this and other extremely lucid and helpful comments.

\section{REFERENCES}

Anagnostopoulou, E. (1997). Clitic left dislocation and contrastive left dislocation. In E. Anagnostopoulou, H. van Riemsdijk, \& F. Zwarts (Eds.), Materials on left dislocation (pp. 151-192). Amsterdam: John Benjamins.

Belletti, A., Bennati, E., \& Sorace, A. (2007). Theoretical and developmental issues in the syntax of subjects: Evidence from near-native Italian. Natural Language and Linguistic Theory, 25, $657-689$.

Bialystok, E., Craik, F. I. M., Green, D. W., \& Gollan, T. H. (2009). Bilingual minds. Psychological Science in the Public Interest, 10, 89-129.

Birner, B. J., \& Ward, G. (1998). Information status and noncanonical word order in English. Amsterdam: John Benjamins.

Boeckx, C. (2003). Islands and chains: Resumption as stranding. Amsterdam: John Benjamins.

Bohnacker, U. (2010). The clause-initial position in L2 Swedish declaratives: Word order variation and discourse pragmatics. Nordic Journal of Linguistics, 33, 105-143. 
Slabakova: Second language knowledge of the syntax-discourse interface

Brunetti, L. (2009). Discourse functions of fronted foci in Italian and Spanish. In A. Dufter \& D. Jacob (Eds.), Focus and background in romance languages (pp. 43-81). Amsterdam: John Benjamins.

Brunetti, L., Bott, S., Costa, J., \& Vallduví, E. (2011). A multilingual annotated corpus for the study of information structure. Paper presented at the Grammar and Corpora 2009 Conference.

Büring, D. (2003). On D-trees, beans and B-accents. Linguistics and Philosophy, 26, 511545.

Chafe, W. L. (1976). Givenness, contrastiveness, subject, topic, and point of view. In C. Li (Ed.), Subject and topic. New York: Academic Press.

Chomsky, N. (2001). Derivation by phase. In M. Kenstowicz (Ed.), Ken Hale: A life in language (pp. 1-51). Cambridge, MA: MIT Press.

Cinque, G. (1983). 'Topic' constructions in some European languages and 'connectedness.' In K. Ehlich \& H. van Riemsdijk (Eds.), Connectedness in sentence, discourse and text: Proceedings of the Tilburg Conference held on 25 and 26 January 1982. Tilburg: Katholieke Hogeschool.

Cinque, G. (1990). Types of A'-dependencies. Cambridge, MA: MIT Press.

Collins, C., Trofimovich, P., White, J., Cardoso, W., \& Horst, M. (2009). Some input on the easy/difficult grammar question: An empirical study. Modern Language Journal, 93, 336-353.

Crain, S., \& Pietroski, P. (2002). Why language acquisition is a snap. Linguistic Review, 19, 163183.

Demirdache, H. (1991). Resumptive chains in restrictive relatives, appositives and dislocation structures. Unpublished doctoral dissertation, MIT.

Donaldson, B. (2011). Left-dislocation in near-native French. Studies in Second Language Acquisition, $33,399-432$.

Donaldson, B. (2012). Syntax and discourse in near-native French: Clefts and focus. Language Learning, 62, 902-930.

Ellis, N. (2002). Frequency effects in language processing. Studies in Second Language Acquisition, 24, 143-188.

Ellis, N. (2006). Language acquisition as rational contingency learning. Applied Linguistics, 27, 1-24.

Frey, W. (2004). Notes on the syntax and the pragmatics of German left dislocation. In H. Lohnstein \& S. Trissler (Eds.), The syntax and semantics of the left sentence periphery (pp. 203-233). Berlin: Mouton de Gruyter.

Gass, S., \& Mackey, A. (2002) Frequency effects and second language acquisition: A complex picture? Studies in Second Language Acquisition, 24, 249-260.

Gass, S., \& Selinker, L. (Eds.). (1993). Language transfer in language learning. Amsterdam: John Benjamins.

Green, D. W. (1986). Control, activation and resource. Brain and Language, 27, 210-223.

Green, D. W. (1998). Mental control of the bilingual lexico-semantic system. Bilingualism: Language and Cognition, 1, 67-81.

Gregory, M., \& Michaelis, L. (2001). Topicalization and left dislocation: A functional opposition revisited. Journal of Pragmatics, 33, 1665-1706.

Grewendorf, G. (2002). Left dislocation as movement. Georgetown University Working Papers in Theoretical Linguistics, 2, 31-81.

Grohmann, K. (2003). Prolific domains. Amsterdam: John Benjamins.

Gundel, J. K. (1998a). On different kinds of focus. In P. Bosch (Ed.), Focus: Linguistic, cognitive and computational perspectives (pp. 293-305). Cambridge: Cambridge University Press.

Gundel, J. K. (1988b). Universals of topic-comment structure. In M. Hammond, E. Moravczik, \& J. Wirth (Eds.), Studies in syntactic typology (pp. 209-239). Amsterdam: John Benjamins.

Halliday, M. A. K. (1967). Notes on transitivity and theme in English: Part II. Journal of Linguistics, $3,199-244$.

Hopp, H. (2009). The syntax-discourse interface in near-native SLA: Off-line and on-line performance. Bilingualism: Language and Cognition, 12, 463-483.

Horvath, J. (2010). "Discourse features," syntactic displacement and the status of contrast. Lingua, $120,1346-1369$.

Ivanov, I. (2009). Second language acquisition of Bulgarian object clitics: A test case for the interface hypothesis. Unpublished doctoral dissertation, University of Iowa.

Ivanov, I. (2012). L2 acquisition of Bulgarian clitic-doubling: A test case for the interface hypothesis. Second Language Research, 28, 345-368. 
Slabakova: Second language knowledge of the syntax-discourse interface

Iverson, M., Kempchinsky, P., \& Rothman, J. (2008). Interface vulnerability and knowledge of the subjunctive/indicative distinction with negated epistemic predicates in L2 Spanish. EUROSLA Yearbook, 8, 135-163.

Jackendoff, R. (1972). Semantic interpretation in generative grammar. Cambridge, MA: MIT Press.

Kempchinsky, P. (2008). How much structure does the left periphery need? Paper presented at the Linguistic Symposium on Romance Languages 38, University of Illinois-Urbana Champaign.

Kiss, K. E. (1998). Identificational focus versus information focus. Language, 74, 245-273.

Kroch, A. (2001). Syntactic change. In M. Baltin \& C. Collins (Eds.), The handbook of contemporary syntactic theory (pp. 698-729). Oxford: Basil Blackwell.

Kroll, J. F., Bobb, S. C., Misra, M. M., \& Guo, T. (2008). Language selection in bilingual speech: Evidence for inhibitory processes. Acta Psychologica, 128, 416-430.

Lambrecht, K. (1994). Information structure and sentence form: Topic, focus and the mental representation of discourse referents. Cambridge: Cambridge University Press.

López, L. (2009). A derivational syntax for information structure. Oxford: Oxford University Press.

Marian, V., \& Spivey, M. J. (2003). Competing activation in bilingual language processing: Within and between-language competition. Bilingualism: Language and Cognition, 6, 97-115.

Montrul, S. (2011). Interfaces and incomplete acquisition. Lingua, 121, 591-604.

Neeleman, A., Titov, E., van de Koot, H., \& Vermeulen, R. (2009). A syntactic typology of topic, focus and contrast. In J. Van Craenenbroeck (Ed.), Alternatives to cartography (pp. 15-52). Berlin: Mouton de Gruyter.

Neeleman, A., \& van de Koot, H. (2008). Dutch scrambling and the nature of discourse templates. Journal of Comparative Germanic Linguistics, 11, 137-189.

O'Grady, W., Lee, M., \& Kwak, H.-Y. (2009). Emergentism and second language acquisition. In W. Ritchie \& T. Bhatia (Eds.), Handbook of second language acquisition (pp. 69-88). Bingley: Emerald Group.

Postolache, O. (2005). Information structure in written English: A corpus study. Paper presented at the IGK colloquium. Retrieved from http://www.coli.uni-saarland.de/projects/ irtg/contents/Colloquium/WS-05/oana.pdf

Prince, E. F. (1992). The ZPG letter: Subjects, definiteness, and information status. In S. Thompson \& W. Mann (Eds.), Discourse description: Diverse analyses of a fund raising text (pp. 295-325). Amsterdam: John Benjamins.

Reinhart, T. (1981). Pragmatics and linguistics: An analysis of sentence topics. Philosophica, 27, $53-93$

Reinhart, T. (2006). Interface strategies. Cambridge, MA: MIT Press.

Rizzi, L. (1997). The fine structure of the left periphery. In L. Haegeman (Ed.), Elements of grammar (pp. 281-337). Dordrecht: Kluwer.

Roberts, L., Gullberg, M., \& Indefrey, P. (2008). Online pronoun resolution in L2 discourse: L1 influence and general learner effects. Studies in Second Language Acquisition, 30, 333-357.

Roeper, T. (2000). Universal bilingualism. Bilingualism: Language and Cognition, 2, 169-185.

Rothman, J. (2009). Pragmatic deficits with syntactic consequences: L2 pronominal subjects and the syntax-pragmatics interface. Journal of Pragmatics, 41, 951-973.

Rothman, J., \& Slabakova, R. (2011). The mind-context divide: On linguistic interfaces and language acquisition. Lingua, 121, 568-576.

Schwartz, B. D., \& Sprouse, R. A. (1996). L2 cognitive states and the full transfer/full access model. Second Language Research, 12, 40-72.

Slabakova, R. (2006). Is there a critical period for the acquisition of semantics? Second Language Research, 22, 302-338.

Slabakova, R., \& Garcia Mayo, M. del P. (2012). The L3 syntax-discourse interface. Paper presented at the Symposium on Third Language (L3) Acquisition: A Focus on Cognitive Approaches, Vitoria-Gasteiz, May 24-25.

Slabakova, R., \& Ivanov, I. (2011). A more careful look at the syntax-discourse interface. Lingua, $121,637-651$.

Slabakova, R., Kempchinsky, P., \& Rothman, J. (2012). Clitic-doubled left dislocation and focus fronting in L2 Spanish: A case of successful acquisition at the syntax-discourse interface. Second Language Research, 28, 319-343.

Slabakova, R., Rothman, J., \& Kempchinsky, P. (2011). Gradient competence at the syntax discourse interface. EUROSLA Yearbook, 11, 218-243. 
Slabakova: Second language knowledge of the syntax-discourse interface

Sorace, A. (2003). Near-nativeness. In C. J. Doughty \& M. H. Long (Eds.), The handbook of second language acquisition (pp. 130-152). Oxford: Blackwell.

Sorace, A. (2005). Selective optionality in language development. In L. Cornips \& K. P. Corrigan (Eds.), Syntax and variation: Reconciling the biological and the social (pp. 55-80). Amsterdam: John Benjamins.

Sorace, A. (2011). Pinning down the concept of "interface" in bilingualism. Linguistic Approaches to Bilingualism, 1, 1-33.

Sorace, A., \& Filiaci, F. (2006). Anaphora resolution in near-native speakers of Italian. Second Language Research, 22, 339-368.

Tsimpli, I., \& Sorace, A. (2006). Differentiating interfaces: L2 performance in syntax-semantics and syntax-discourse phenomena. In D. Bamman, T. Magnitskaia, \& C. Zeller (Eds.), Proceedings of the 30th annual Boston University Conference on Language Development (Vol. 2, pp. 653664). Somerville, MA: Cascadilla Press.

Vainikka, A., \& Young-Scholten, M. (1996). Gradual development in L2 phrase structure. Second Language Research, 12, 7-39.

Valenzuela, E. (2005). L2 ultimate attainment and the syntax-discourse interface: The acquisition of topic constructions in non-native Spanish and English. Unpublished doctoral dissertation, McGill University, Montreal.

Valenzuela, E. (2006). L2 end state grammars and incomplete acquisition of the Spanish CLLD constructions. In R. Slabakova, S. Montrul, \& P. Prévost (Eds.), Inquiries in linguistic development: In honor of Lydia White (pp. 283-304). Amsterdam: John Benjamins.

Vallduví, E. (1992). The informational component. New York: Garland.

Vallduví, E., \& Vilkuna, M. (1998). On rheme and konstrast. Syntax and Semantics, 29, 79-108.

van Haaften, T., Smits, R., \& Vat, J. (1983). Left dislocation, connectedness and reconstruction. In K. Ehlich \& H. Van Riemsdijk (Eds.), Connectedness in sentence, discourse and text. Tilburg, Netherlands: Tilburg University, Department of Language and Literature.

Ward, G. L. (1988). The semantics and pragmatics of preposing. Unpublished doctoral dissertation, University of Pennsylvania.

White, L. (1989). Universal grammar and second language acquisition. Amsterdam: John Benjamins.

White, L. (2009). Grammatical theory: Interfaces and L2 knowledge. In W. Ritchie \& T. Bhatia (Eds.), The new handbook of second language acquisition (pp. 49-68). Leeds: Emerald Group.

Yang, C. (2002). Knowledge and learning in natural language. New York: Oxford University Press.

Yang, C. (2004). Universal grammar, statistics, or both. Trends in Cognitive Sciences, 8, 451-456.

Yang, C. (2010). Three factors in language variation. Lingua, 120, 1160-1177.

Zubuzarreta, M.-L. (1998). Prosody, focus and word order. Cambridge, MA: MIT Press. 